\title{
Frequency of Thyrotoxicosis in Patient with One Sided Exophthalmos
}

\author{
Tahreem Zafar ${ }^{4}$, Shumaila Perveen², Nisar Khan ${ }^{3}$, Salman Khan ${ }^{3}$, Tahseen Ahmed ${ }^{1, *}$ \\ ${ }^{1}$ Institute of Pharmaceutical Sciences, PUMHS, Nawab Shah, Pakistan \\ ${ }^{2}$ Faculty of Pharmacy, University of Sindh, Jamshoro, Pakistan \\ ${ }^{4}$ Mufti Mehmood Memorial Hospital, Dera Ismail Khan, Pakistan
}

${ }^{3}$ GMC MTI, Dera Ismail Khan, Pakistan

\section{Authors' Contributions \\ 1 Conception \& study design \\ 3 Data Collection \& Processing \\ 4 Data Analysis and/or Interpretation \\ 2 Drafting of Manuscript \\ 5 Critical Review}

\section{Article info.}

Received: October 25, 2019

Accepted: September 10, 2020

Funding Source: Nil

Conflict of Interest: Nil

Cite this article: Zafar T, Perveen S, Khan N,

Khan S, Ahmed T. Frequency of

Thyrotoxicosis in Patient with One Sided

Exophthalmos. RADS J Pharm Pharm Sci.

2020; 8(2):81-84

*Address of Correspondence Author: tahseen.channa89@gmail.com

\section{ABSTRACT}

Background: Thyroid associated Opthalmo-pathy is a condition of lid retraction causing a staring appearance. This occurs in any form of thyrotoxicosis as a result of sympathetic overactivity. Exophthalmos is the forward protrusion of eye ball beyond the orbital rim.

Material \& Methods: This case series was observed in medical department Mufti Mehmood Teaching Hospital DIKhan, Pakistan over a period of eight months from February 2018 to September 2018. Detailed history with reference of duration of illness, mode of onset, progression and associated symptoms like fever, pain, diplopia and loss of vision was taken. Complete examination of orbit, eyelid, anterior and posterior segment was done. Routine Investigations along with special diagnostic tests like TFTs and MRI were performed to aid etiological diagnosis.

Results: A total 47 patients were observed during this study period. Out of these $20(21.27 \%)$ were male and $27(57.44 \%)$ were female with male to female ratio $1: 1.35$ with mean age of 32 years. Out of 47 patients $30(63.82 \%)$ patients were having thyrotoxicosis as a cause of exophthalmos, $10(21.27 \%)$ were having retrobulbartumour, $5(10.63 \%)$ patients were with cavernous sinus thrombosis and $2(4.25 \%)$ patients were having idiopathic cause of exophthalmos.

Conclusion: Thyrotoxicosis is the common cause of one sided exophthalmos and should be considered in all patients with one sided exophthalmos.

Keywords: Proptosis, Thyrotoxicosis, Thyroid eye disease.

\section{INTRODUCTION}

Thyroid associated Opthalmo-pathy is a condition of lid retraction causing a staring appearance. This occurs in any form of thyrotoxicosis as a result of sympathetic overactivity [1]. Proptosis is the forward movement of the globe in relation to the skull whereas Henderson reserves the use of word exophthalmos for those cases of Proptosis secondary to endocrinological dysfunction. The exact clinical diagnosis of proptosis's cause is difficult due to inaccessibility of the contents of orbit. [2] In 5-10\% of the cases severe exophthalmos occur due to increased retro-orbital fat and lymphocytic infiltration of extraocular muscles. Proptosis is usually bilateral but can be unilateral $(10 \%)$ and is measured by using Hertel Exophthalmometer. The normal value of protrusion is $21 \mathrm{~mm}$ in white men and $19 \mathrm{~mm}$ in white women, $24 \mathrm{~mm}$ in black men and $23 \mathrm{~mm}$ in black women, $19.9 \mathrm{~mm}$ in Asian men and $18.6 \mathrm{~mm}$ in Asian women 
[3]. Theincidence of exophthalmos is $16 / 100,000$ in women and $3 / 100,000$ in men per year. Study shows that prevalence of exophthalmos is higher in Europeans at a rate of $42 \%$ versus $7.7 \%$ in Asians. Europeans are 6.4 times more prone to have Grave's Opthalmo-pathy [4]. Thyroid eye disease is the most common cause of unilateral and bilateral Proptosis. This disease is present in almost $50 \%$ of Graves disease cases and 5\% patients develop severe diseases with dysthyroid optic neuropathy. Some other causes of Proptosis arecellulitis,mucormycosis, retro orbital tumors and cavernous sinus thrombosis. Pathogenesis of thyroid eye disease derives from a complex interplay of endogenous and exogenous factors, where the former is a non-modifiable factor while the latter can be modified $[5,6]$.

It has been observed that preventive actions such as quitting smoking may (up to some extent) prevent progression and severity of graves' orbito-pathy. Studies also show that graves' orbitopathy is best treated by immuno-suppression when active or by surgery in an inactive scenario. Additionally, some patients may require rehabilitative surgery (e.g. orbital decompression and/or eyelid surgery) when the disease course ends. The aim of this study was to know the frequency of thyrotoxicosis and other causes of one sided exophthalmos and treatable causes should be sort out and treated.

\section{MATERIALS AND METHODS}

This case series was observed at Medical Department Mufti Mehmood Teaching Hospital DIKhan, Pakistan over a period of eight monthsfrom February 2018 to September 2018. Patients with one sided exophthalmos were included in this study. Patients with bilateral exophthalmos and other ophthalmic problem were excluded from the study.Detailed history with reference of duration of illness, mode of onset, progression and associated symptoms like fever, pain, diplopia and loss of vision was taken. Complete examination of orbit, eyelid, anterior and posterior segment was done. Routine Investigations along with special diagnostic tests like TFTs and MRI were performed to aid etiological diagnosis.

\section{RESULTS}

Total 47 patients with one sided exophthalmos were observed during study period. Among these 20 $(42.5 \%)$ were male and $27(57.5 \%)$ were female. The mean age was 32 years with age range was 35year (15-50years) (Table 1). The majority of patients 28(59.5\%) were between 21 to 30 years, $8(17.02 \%)$ were between 31 to 40 year, $4(8.51 \%)$ were between 10 to 20 years and only $7(14.89 \%)$ were between 41 to 50years. Regarding the cause of exophthalmos $30(63.8 \%)$ (Table 2 and Figure 1) were having thyrotoxicosis out of which $10(21.2 \%)$ were male and $20(42.55 \%)$ were female. $10(21.2 \%)$ were having retrobulbartumour with $5(10.6 \%)$ male and $5(10.6 \%)$ female ratio.

Cavernous sinus thrombosis was observed in $5(10.6 \%)$ patients with $3(6.38 \%)$ male and $2(4.25 \%)$ female. Only $2(4.25 \%)$ patients were having thyrotoxicosis with idiopathic cause and both were male as shown in Table 3, Figure $\mathbf{2}$ and Figure $\mathbf{3}$.

Table 1. Gender wise distribution of study subjects.

\begin{tabular}{|c|c|c|}
\hline Gender & Number & Frequency \\
\hline Male & 20 & $42.5 \%$ \\
\hline Female & 27 & $57.5 \%$ \\
\hline
\end{tabular}

Table 2. Age wise distribution of study groups.

\begin{tabular}{|c|c|c|}
\hline Age Group & Number & Frequency \\
\hline $\mathbf{1 0 - 2 0}$ & 04 & $8.51 \%$ \\
\hline $\mathbf{2 1 - 3 0}$ & 28 & $59.57 \%$ \\
\hline $\mathbf{3 1 - 4 0}$ & 8 & $17.02 \%$ \\
\hline $\mathbf{4 1 - 5 0}$ & 7 & $14.89 \%$ \\
\hline
\end{tabular}

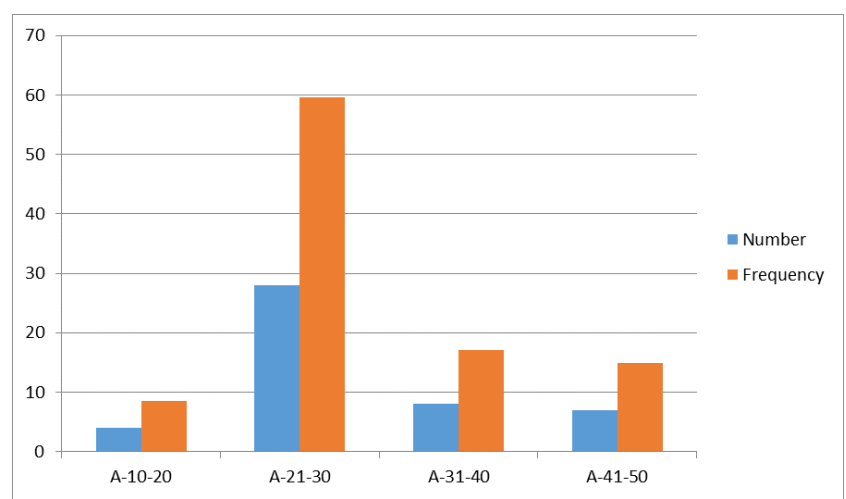

Figure 1. Graphatical representation of Age groups of study subjects. 
Table 3. Etiological distribution of Proptosis with reference to Gender.

\begin{tabular}{|c|c|c|c|}
\hline Condition & $\begin{array}{c}\text { Male } \\
\mathbf{N}(\%)\end{array}$ & $\begin{array}{c}\text { Females } \\
\mathbf{N}(\%)\end{array}$ & Total \\
\hline Exopthalmos & $10(33.3 \%)$ & 20 & 30 \\
\hline Retrobulbar Tumor & $5(50 \%)$ & $5(50 \%)$ & 10 \\
\hline $\begin{array}{c}\text { Cavernous Sinus } \\
\text { Thrombosis }\end{array}$ & $3(60 \%)$ & $2(40 \%)$ & 5 \\
\hline Thyrotoxicosis & $2(100 \%)$ & - & 02 \\
\hline Total & 20 & 27 & 47 \\
\hline
\end{tabular}

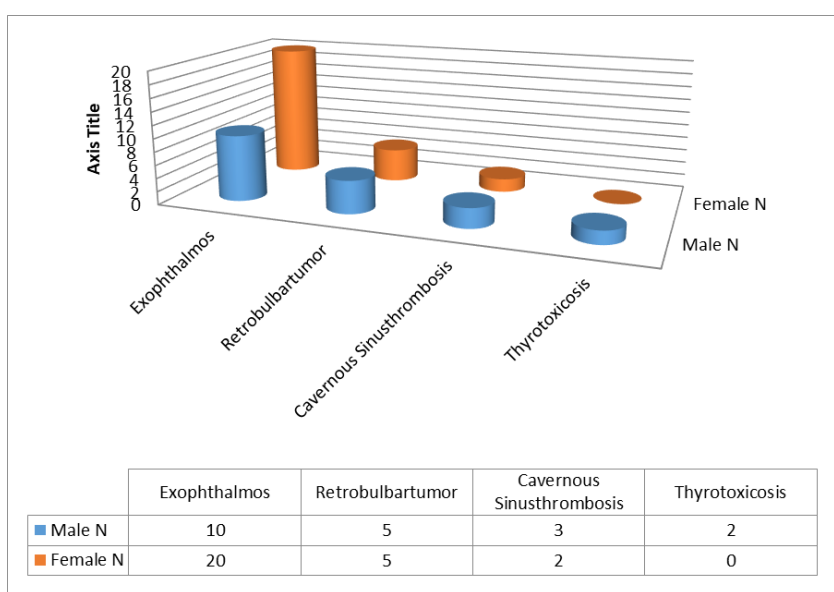

Figure 2. Etiological distribution of Proptosis with reference to Gender.

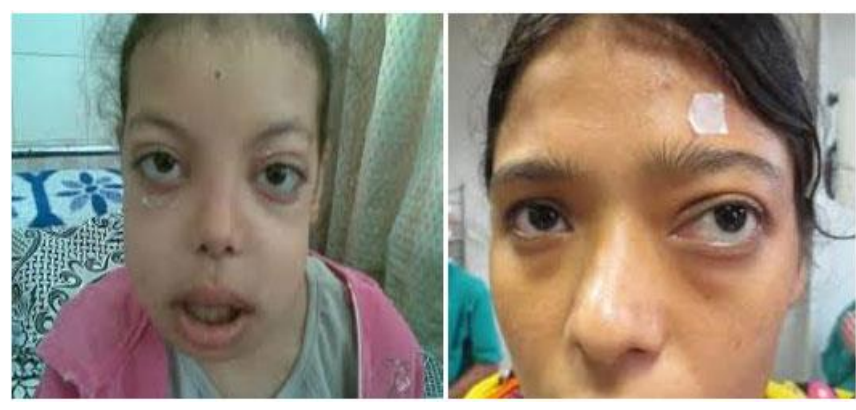

Figure 3. Patients with exophthalmos and Proptosis.

\section{DISCUSSION}

Thyroid eye disease is a functionally debilitating disease seen all over the world often disfiguring and impairing quality of life. Most studies in world have shown a raised female to male ratio of patients primarily affected by thyroid eye disease. In our study it was observed that female gender was primarily affected more by Thyroid eye disease with a ratio of 1:1.35. A study from Iran by Sara Gharib et al [7] reported this ratio as $1: 1.7$. A study by M.L Tanda et al [8] had a ratio of 1:3 having mild grave's orbitopathy. A study by NithinTenja et al [9] had a ratio of 1:1.07. Besharti, Etezad-Razavi \& Perros also showed a higher frequency in females [10-12]. It is obvious from the results of this study that young age group with a mean age of 32 year are the main sufferer of one sided exophthalmos. It is consistent with many other studies. Sara Gharib et al [7] reported the mean age of 35 (standard deviation 13.0). M.L. Tanda et al [8] reported the mean age of $45.7 \pm 13.7$ years. In our study thyrotoxicosis was seen as the most common cause of one sided exophthalmos (63.8\%) similar to the study conducted by NithinTeja et al in which thyrotoxicosis and inflammation were the top most causes of one sided exophthalmos. This however is in contrast to the observations of Masud et al [13] where they showed tumor as the most common cause of Proptosis. Among all patients of Proptosis $21.2 \%$ were having retrobulbar tumor which is almost similar to NithinTeja et al [9] (18.51\%) where as in Masud et al [13] study it was $33 \%$. Cavernous sinus thrombosis is the formation of blood clot with in cavernous sinus, a cavity at base of brain which drains deoxygenated blood from brain back to heart. Cavernous sinus thrombosis was observed in $10.6 \%$ in our study where as in study of NithinTeja et al it was only $5.5 \%$. Unilateral Proptosis of unexplained origin may be due to small mass in muscles cone not extending to orbital apex as a simple tumor, cyst or reactive hyperplasia. In our study idiopathic causes were observed in $2(4.2 \%)$ patients similar to the study done by Blegvad that reported 5 cases with idiopathic causes and Gleason also reported a case of idiopathic cause of one sided exophthalmos. DukeElder (1952) prefers to classify it with exophthalmic ophthalmoplegia due to thyroid pituitary disorder. If, during orbital exploration to discover the cause of exophthalmos, nothing is found, a biopsy of the rectus muscle should be taken to exclude dysthyroidism [1419].

\section{CONCLUSION}

Thyrotoxicosis is the commonest cause of one sided exophthalmos. It is recommended to investigate the thyrotoxicosis in all cases of exophthalmos. All the patients with one sided exophthalmos should be advised MRI Brain to look for other causes of exophthalmos. The study also indicates that female and people of younger age group are more involved in thyroid eye disease. 


\section{REFERENCES}

1. Meeks JJ, Weiss J, Jameson JL. Dax 1 is required for testis determination. Nature genetics. 2003;34(1):32-3.https://doi.org/10.1038/ng1141

2. Ackuaku-Dogbe EM, Akpalu J, Abaidoo B. Epidemiology and Clinical Features of Thyroidassociated Orbitopathy in Accra. Middle East Afr J Ophthalmol. 2017; 24(4):183-189. doi: 10.4103/meajo.MEAJO_91_17

3. Erb MH, Kersten RC, Yip CC, Hudak D, Kulwin DR, McCulley TJ. Effect of unilateral blepharoptosis repair on contralateral eyelid position. Ophthalmic Plastic \& Reconstructive Surgery. $2004 \quad ; 20(6): 418-22 . \quad$ doi: 10.1097/01.IOP.0000143714.10858.D4

4. Träisk F, Bolzani R, Tallstedt L, Schworm HD, Ygge J. Saccadic eye movement velocity measured with the infrared reflection and search coil eye-tracking systems in patients with thyroidassociated ophthalmopathy. Strabismus. 2007;15(4):173-80.

5. Delyfer MN, Gaucher D, Govare M, CougnardGrégoire A, Korobelnik JF, Ajana S, Mohand-Saïd $\mathrm{S}$, Ayello-Scheer $\mathrm{S}$, Rezaiguia-Studer $\mathrm{F}$, Dollfus $\mathrm{H}$, Sahel JA. Adapted surgical procedure for Argus II retinal implantation: feasibility, safety, efficiency, and postoperative anatomic findings. Ophthalmology Retina. 2018;2(4):276-87.

6. de Juan E, Hurley DP, Sapira JD. Racial differences in normal values of proptosis. Archives of internal medicine. 1980;140(9):1230-1.

7. Gharib S, Moazezi Z, Bayani MA. Prevalence and severity of ocular involvement in Graves' disease according to sex and age: A clinical study from Babol, Iran. Caspian J Intern Med. 2018; 9(2): 178-183.doi: 10.22088/cjim.9.2.178

8. Tanda ML, Piantanida E, Liparulo L, Veronesi G, Lai A, Sassi L, et al. Prevalence and natural history of Graves' orbitopathy in a large series of patients with newly diagnosed graves' hyperthyroidism seen at a single center. The Journal of Clinical Endocrinology \& Metabolism. 2013;98(4):1443-9.
9. Teja N, Reddy M, Vanama A. An etiological analysis of proptosis. International journal of Research in Medical Sciences. 2015;2(10):2584-8.

10. Besharati MR, Rastegar A. Clinical study of ophthalmopathy in patients with Graves' disease. Asian J Ophthalmol. 2005;7(3):108-12.

11. Etezad-Razavi M, Aboutorabi RB, Zarei-Ghanavati $\mathrm{S}$, et al. Prevalence and severity of ophthalmic manifestations of Graves' disease in Mashhad university endocrine clinics. J Curr Ophthalmol 2006; 19 (3): 14-21

12. Perros $P$, Neoh $C$, Dickinson J. Thyroid eye disease. Bmj. 2009;338:b560..

13. Masud M, Moshirfar M, Shah TJ, Gomez AT, Avila MR, Ronquillo YC. Eyelid Cosmetic Enhancements and Their Associated Ocular Adverse Effects. Medical Hypothesis, Discovery and Innovation in Ophthalmology. 2019; 8(2):96.

14. Bartalena L, Marcocci C, Bogazzi F, Manetti L, Tanda ML, Dell'Unto E, et al. Relation between therapy for hyperthyroidism and the course of Graves' ophthalmopathy. New England Journal of Medicine. 1998; 338(2):73-8.

15. Mortada A. Unilateral proptosis of unexplained origin.The British journal of ophthalmology. 1965;49(10):547.

16. Sharma P, Tiwari PK, Ghimire PG, Ghimire P. Role of computed tomography in evaluation of proptosis. Nepal Journal of Medical Sciences. 2013;2(1):34-7.

17. Chen Y, Zhang X, Hu X, Deng Y, Chen J, Li S, et al. The potential role of a self-management intervention for benign prostate hyperplasia. Urology. 2012;79(6):1385-9.

18. Lee AJ, Rochtchina E, Wang JJ, Healey PR, Mitchell P. Open-angle glaucoma and systemic thyroid disease in an older population: The Blue Mountains Eye Study. Eye. 2004;18(6):600-8.

19. Adli OE, Elammari JE, Elfassi MJ, Farih MH. Unilateral Exophthalmos Revealing Metastatic Prostate Cancer. Urology. 2012;79(3):e40-1. 